\title{
Analyzing the Current Situation of E-learning at Kabul Polytechnic University
}

\author{
Hamidullah Sokout \\ Graduate School of Science and Technology \\ Kumamoto University \\ Japan \\ +81-80-6514-2440 \\ hamid.sokout@gmail.com
}

\author{
Tsuyoshi Usagawa \\ Graduate School of Science and Technology \\ Kumamoto University \\ Japan \\ +81-96-342-3622 \\ tuie@cs.kumamoto-u.ac.jp
}

\begin{abstract}
Nowadays Information and Communication Technologies (ICTs) are widely used in a variety of fields all over the world. As for instance, use of ICT in education has transformed the way of delivering instructions from a traditional to modern and effective manner. As Afghanistan proceeds to move forward the higher instruction openings for its citizens, instruction through cutting edge strategies and methods such as e-learning must be considered. Kabul Polytechnic University (KPU) has consistently aligned itself with the Ministry of Higher Education's strategic plan and has taken major steps towards the implementation of elearning. Recently, a pilot implementation of Moodle has taken place. This paper provides (i) an overview of ICT for education (ICT4E) in Afghanistan; (ii) evaluates the current status of elearning at KPU; (iii) reports on pilot implementation of Moodle; (iv) identifies the potential challenges and (v) proposes possible solutions to overcome the challenges.
\end{abstract}

\section{CCS Concepts}

-Applied computing $\rightarrow$ Education $\rightarrow$ E-learning

\section{Keywords}

ICT for Education; e-learning; Moodle; Kabul Polytechnic University

\section{INTRODUCTION}

An e-learning refers to learning being facilitated and supported through the use of electronic media and ICT. It enables the learners to access their particular learning contents at different times with more interactive process. Due to the major benefits of e-learning that include (cost effectiveness, faster delivery, lower environmental impact and effective learning) many educational sectors and institutions around the world facilitate the e-learning services to their learners.

According to [1], during 1980 and 1990 e-learning programs have been created to supplement, upgrade and support process of educating and learning with the work of electronic instruments or computerized media. Since at that point, a number of sub-

\footnotetext{
Permission to make digital or hard copies of part or all of this work for personal or classroom use is granted without fee provided that copies are not made or distributed for profit or commercial advantage and that copies bear this notice and the full citation on the first page. Copyrights for third-party components of this work must be honored. For all other uses, contact the Owner/Author.

ICEMT 2018, July 2-4, 2018, Okinawa, Japan

(C) 2018 Copyright is held by the owner/author(s).

ACM ISBN 978-1-4503-6525-3/18/07 ..\$15.00
}

https://doi.org/10.1145/3206129.3239428 categories of e-learning have risen as a huge number of sorts and shapes: computer-based trainings, online educating, interactive media learning, virtual learning, Massive Open Online Courses (MOOCs), learning communities, virtual classrooms and etc.

The objectives of this study are to assess the current status of elearning in KPU, to highlight the potential challenges that against the adoption of e-learning in university level in Afghanistan and KPU in particular and to provide possible solutions to address the current challenges and foster the implementation of e-learning.

The result of this study are expected to provide input for the implementation of Learning Analytics to ensure the effectiveness of LMS to learners behaviors and paves the way for sustainable teaching and learning environment in future.

\section{OVERVIEW OF ICT FOR EDUCATION IN AFGHANISTAN}

In current century higher education plays a key role in a nation, it leads the nations towards a sustainable development and to gauge the pace of progress. Lack of higher educated people in a country is hurdle for the economic development, social development and nation building process. Higher education determines the characteristics of a society and introduces a nation to the worldwide. Afghanistan is one the country that faced three decades war, which results devastated education systems and institutions. After the overthrow of the Taliban in late 2001, the new administration received substantial international aid to restore the education system. According to the report of United Sate Agency for International Development (USAID) , approximately, 900,000 male students attended schools without the appearance of girls in 2002. According to the Asia Foundation reports, around $75 \%$ of Afghan students are satisfied with their daily educational activities and the availability of opportunities [2].

Education system in Afghanistan includes K-12, semi-higher education and higher education which are managed by the Ministry of Education (MoE) and Ministry of Higher Education (MoHE). School level in Afghanistan divided into three levels includes (i) primary schools which covers 1-6 grades, (ii) secondary schools in 7-9 grades, and (iii) high schools that cover 10-12 grades. After graduation from the high schools, students take the national university entrance examination (Kankor) so that educational authorities can determine who is eligible to join semihigher education and higher education institutions. Afghanistan higher education institutions provide higher education for undergraduate and graduate students.

However, still there are many challenges with respect to the improvement of the overall quality of educational in Afghanistan. 
Based-on United Nations Development Program (UNDP) report in 2014, Afghanistan continues to be ranked at the low level of the human development index (index 0.468, Rank 169) [3]. Similarly, adult literacy rate is $39 \%$ (15+ years) for male and $13 \%$ for females only [4]. All these issues and human development indicators derived from the past three decades war, insecurity and gap in education between the rich and poor people.

In 2003, the Ministry of Communication and Information Technology (MoCIT) with the support and cooperation of MoE, MoHE and associated institutions decided to take effective steps towards the implementation and launch of e-learning programs in Afghanistan [5]. However, limited access and lack of capacity to deal and interact with ICTs in educational institutions is another big challenge, which still remains unsolved.

\subsection{Cisco Networking Academy Program (CNAP) - 2002}

The first comprehensive e-learning program launched in Afghanistan was the Cisco Networking Academy Program (CNAP) which launched its first generation of Academies in Kabul, hosted by Kabul University (KU), Faculty of Computer Science, the MoCIT Training Center and the Ministry of Women's Affairs. CNAP was introduced and initiated in Kabul in 2002. Due to the program success, the program expanded to secondary provinces in 2004. CNAP Afghanistan currently includes one regional academy at KU and nine local academies hosted at the Ministry of Women's Affairs, MoCIT, Kabul Education University (KEU), Bamyan, Khost, Mazar, Nangarhar, Kandahar and Herat provinces. The program will also launch some of its local academies in other parts of the country in near future [6].

\subsection{Afghan's Next Generation e-Learning (ANGeL) - 2005}

Afghanistan Next Generation e-Learning (ANGeL) center was the second comprehensive e-learning program that was launched at $\mathrm{KU}$ in 2005 . This center was designed to prepare the capability of teaching and learning in university level to help teachers and students to improve their knowledge, attitude and skills using ICTs. ANGeL also provides online courses for university students to increase their IT skills and Internet knowledge, usage of applications and software applications. ANGeL currently has several branches in Kabul, Balkh, Herat, Khost, Nangarhar and Kandahar universities. The major three branches are dedicated for KU, KPU and Kabul University of Medical Sciences (KUoMS) students and academic staff [5].

\subsection{Distance Training Program - 2005}

Distance Training Program was the third well-known e-learning program which was successfully implemented by the MoHE in the country. The major objective was to provide tele-video conference among the universities across the country in order to provide the required lectures to the distance universities which are facing lack of professional lecturers and educational facilities. This program will help them to develop their academic and professional skills accordingly.

Furthermore, some other e-learning programs established by several international parties to support and improve teaching and learning in Afghanistan. For instance, United Nations Educational, Scientific and Cultural Organization (UNESCO) funded Education Radio and TV in 2004. The program aimed to equip the National Educational and Radio TV center with Internet connection to serve Afghan new generation. In addition, United State Agency for International Development (USAID) with partnership to Kabul University established Afghan eQuality Alliance; in order to increase the number of Afghans professional and students who are ICT capable [7]. In addition, IT center of Kabul University (ITCK) initiated for the purpose of teaching and learning in 2003.

These platforms give opportunities to Afghan youths to interact worldwide and make academic literature. Nowadays, we can find many e-learning programs around the country, and the majority of participants who attended the initial training courses and using the e-learning programs are optimistic about the potential benefits of e-learning and emphasize for more investment of such kinds of facilities in different level of education. Moreover, the e-learning policy already set by the MoHE with the cooperation of MoCIT to embed and integrate the variety of e-learning programs for teaching and learning. This policy covers higher education, schools and semi-higher education institutions. Implementation of such programs will have a positive effect to the economic and social development of Afghanistan [8].

In Afghanistan, which has spent many years in the war and undergoes ineligible damage to educational institutions, it is easy for students to use e-learning to reduce the shortage of school materials, colleges and faculty. Most importantly, in the insecure and remote areas of the country that cannot be taught for people of the society, especially for the females. As a result, we have tried to create e-learning for the first time in the country with the launch of these systems.

According to the five-year strategic plan of MoHE of Afghanistan the program of e-learning divided into 3 major phases which laid out over the next three years.

\section{1) Enrichment (2015-2016)}

In this phase, a general assessment of the Universities and higher education institutions is carried out and the requirements are listed and graded accordingly. In the enrichment phase, equipping departments with e-class facilities, improving faculty capacity, introducing professors to e-learning, participating in conferences, sharing in the appropriate chapters, and raising the Internet are included, which provides a suitable platform for the second phase.

\section{2) Blended Learning (2017-2018)}

In this regard, the development of digital libraries, the establishment of university-level e-learning departments, capacity building for professors, the creation of integrated training courses and the monitoring of quality assurance are included.

\section{3) Virtual Learning (2018-2020)}

In this phase, creating virtual universities of virtual classes will be measured according to the standards of e-learning. The development of integrated training courses will be taken to fully integrate the classroom into virtual classes, and there will be ongoing validation efforts [9].

In the initial step of this strategy plan MoHE is committed in implementing e-learning in Afghan public universities, particularly four major Kabul public universities (KU, KPU, $\mathrm{KMU}$, and KEU) and four major provincial universities (Herat University, Kandahar University, Balkh University and Nengarhar University).

KPU is one of the major technical public university in Kabul that already aligned itself with the Ministry of Higher Education's 
five-year strategy plan and is ready for implementation of elearning.

\section{ANALYZING THE CURRENT SITUATION OF E-LEARNING}

What we feel now is very different from 12 years back; the use of information and communication technology can be seen in a variety of fields. The ICT gives us the innovation and prosperity, which provides the IT Infrastructure and services framework that enable all our people to exploit state-of-the-art information and communication developments.

The overall goal is to create e-learning courses and use of electronic devices in the teaching and learning process.

In addition, by connecting the universities of the country, including four universities in Kabul (KU, KUoMS, KPU and $\mathrm{KEU}$ ) and four top provincial universities (Nengarhar University, Balkh University, Herat University and Kandahar University) can provide a forum for research and information exchange.

\subsection{KPU e-Learning Committee}

KPU e-Learning committee was formed in accordance with the Ministry of Higher Education's e-learning policy in 2015. The members of the committee are composed of active and experienced professors from different faculties where most of them are from Computer Engineering and Informatics Faculty of KPU. The committee has been organizing regular meetings, and has been involved in launching conferences at the KPU and the MoHE for the purpose of launching e-learning programs at the university. The following bullets represent the activities of KPU e-learning committee.
- Quantitative and qualitative assessment of the use of electronic equipment in the teaching process at KPU

- Conducted multiple workshop to enhance capacity building

- Effective use of LMS and the Feedback Management System by 8 faculties since March 2018.

- Launched multiple conferences for awareness of e-learning

- Improved Awareness of KPU professors and staff

- Equipped three classrooms

- Included e-learning in the individual unit professors' departments

- Launched virtual distance learning classes for provincial engineering universities including Kandahar University.

\subsection{Pilot Implementation of Moodle at KPU}

The first time KPU has lunched Moodle platform as a Learning Management System (LMS) in 2017 in order to facilitate learning and teaching via the Internet with tools to enable learners to interact with each other and share learning resources. In this initial stage of learning, students use the LMS for the following purposes.

- To access necessary resources material

- To submit assignments

- To interact with classmates and instructor

During 16 weeks the students interacted with the system, used the necessary resources and submitted their assignments with 2 group works and 4 individual through Moodle platform. The following pie chart (Figure 1) illustrates the grade report of 6 assignments for 43 students.

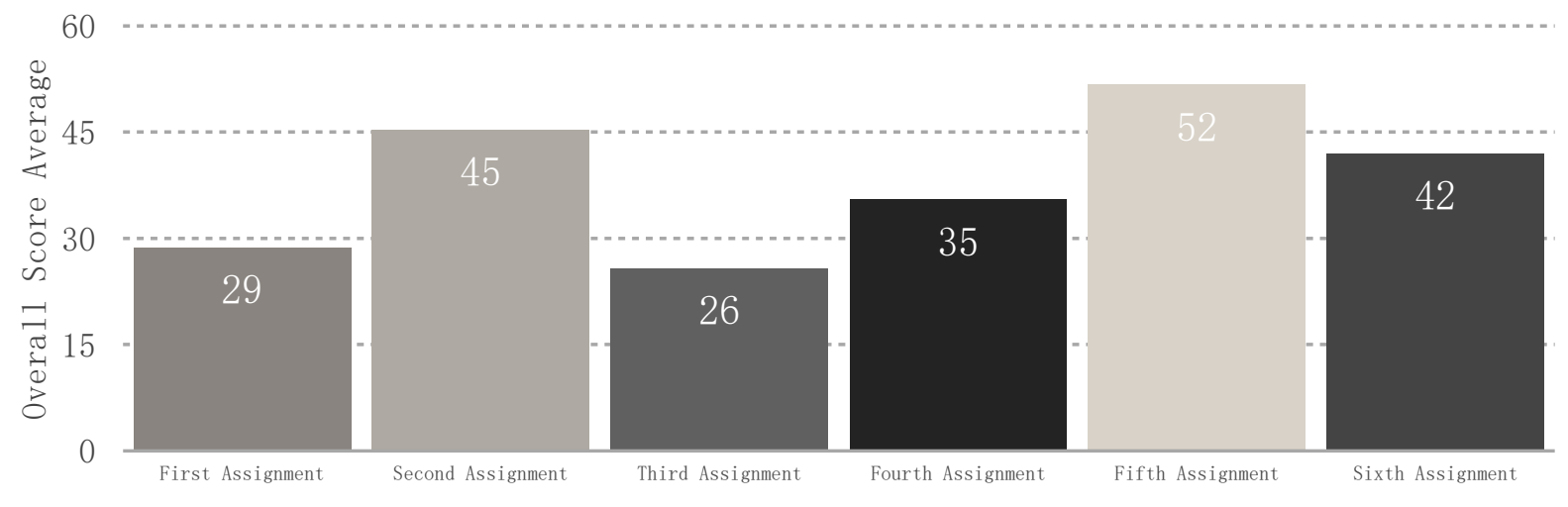

Figure 1. Student's grader report for 6 assignments through Moodle

As shows in the pie chart above out of 6 assignments; the second and third assignments were submitted by groups; each with 4 to 5 persons and the remaining assignments submitted individually.

\subsection{Results}

Moodle platform was successfully tested with 43 students within one semester in academic year 2017 at KPU. However, the scores were not satisfactory due to several reasons, like unfamiliarity with Moodle LMS, lack of experience, and Internet connectivity issues. However, the result shows a dramatically improvement in equality, learners cognitive ability, motivation and competition with less resources.

The purpose for pilot testing was to echo the feedback received from the participants and to know the effectiveness of LMS to their learning behavior.

\section{THE CHALLENGES TO ACHIEVE THE EXPECTED IMPACT OF E-LEARNING AT KPU}

Since, the implementation of new programs have their own problems, such as shortage of professionals and lack of facilities and resources, The following challenges and issues sorted into various categories based-on pilot implementation of Moodle at KPU.

\subsection{Low Reliability of Data}

In spite of the proceeded appropriation and utilization of Learning Management System at KPU, there's small prove to recommend that they are really improving student's learning performance. 
Moreover information retrieved from students' perceptions through studies may not give exact indicators of learning as they rarely indicate the causality of effects. The following pie chart (Figure 2) indicates evaluation result.

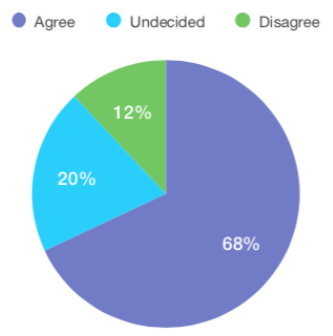

Figure 2. Evaluation result

Of the 25 respondents, $68 \%$ rated their agreements about the overall class and rated it as likely to motivate students.

\subsection{Scarcity of Enough Sources of Education Data and Learning Analytics}

Since the pilot implementation of Moodle at KPU faced with scarcity of enough sources of educational data, measurement and analysis of various data, therefore it is too difficult to understand and optimize learning environments and improve learning and teaching. Ultimately, this requires more advanced strategies for evaluating the effectiveness of LMS to achieve learning goals along with variety of data sources. The latest analytical strategies, particularly Learning Analytics, which has a significant role to play in the future of higher education [10].

Since Learning Analytics focuses to the success of online programs and support the achievement of specific learning goals; therefore there is a critical need to consider site statistics, quizzes, course activities, grade-book scores, enrollment, and assignments as a sources of education data for better implementation of elearning systems.

\subsection{Proper Infrastructure and Quality of Service}

Having proper infrastructure is one of the major requirements for implementation of e-learning programs. Afghanistan is still having problems with reliability of Internet connection, electricity, ICT centers and quality of service. The acquisition and deployment of technology can be slowed down by legal, financial and personal constraints.

\subsection{Pedagogical and Human Resources}

E-learning is a new concept for most of the instructors and students, and it is therefore necessary to enhance their familiarity with the education technology at a certain level. Developing countries mostly face unawareness of the importance or lack of human resources, inappropriate academic curriculum, quality of education and adopting student-centered method.

\subsection{Maintenance and Support}

Since e-learning is a new experience for Afghan universities; therefore support and maintenance is one of the big issue in future of e-learning. In addition, luck of learning analytics to ensure the effectiveness of e-learning systems along with evaluation of learning behaviors of target learners might be the other issues in Afghan public and private universities.

\section{THE SOLUTIONS TO OVERCOME THE CHALLENGES}

The following solutions are proposed to overcome the existing challenges of e-learning in Afghanistan, and KPU in particular.

\subsection{Governance and Implementation of $\mathrm{E}$ - learning Strategic Plan}

MoHE of Afghanistan already established a national e-learning plan that include basic level, high school level, college and university level with their clear target. These kinds of strategic plans could be an equipment deployment plan, but the important parts of this plan would be its educational approach, teaching and learning approaches, methods and contents that must be constant from the primary level to higher education. With a clear national e-learning policy, it is not difficult to make the education environment more result-oriented.

However, according the report of MoHE, the overall ICT Centers and ICT Facilities for public universities is growing since 2015. The Figure 3 reveals progress of ICT Centers for seven public universities; and Figure 4 indicates ICT facilities progress for ten public universities in Afghanistan.

As shows in Figures 3 and 4, among 17 public universities around the country; 29\% ICT centers are established and about $57 \%$ of them under construction. Meanwhile ICT facilities and equipment' has already provided for $40 \%$ of universities and $50 \%$ of them are in-progress.

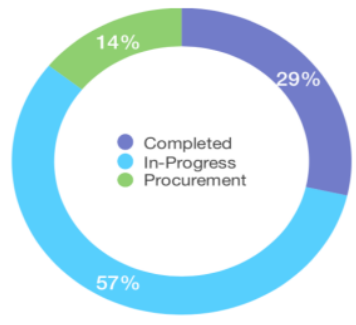

Figure 3. Progress of ICT Centers

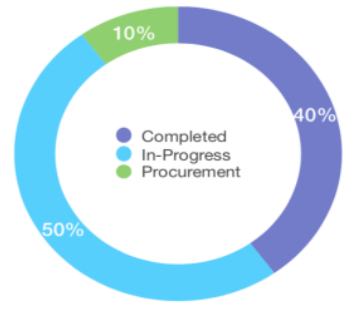

Figure 4. Progress of ICT Facilities
Among the ICT Centers, 5 centers were established by the support of ZiiK TU-Berlin since 2003. MoHE planned to establish 12 additional ICT centers along with IT labs, ICT equipment and facilities to all universities by the end of 2020 with the support of HEDP [9].

\subsection{Improve Teacher Training on Use of ICTs}

The key success on introduction of ICT in education is the teachers training. It is very important to make teachers confident to use ICT in education. To make the general education more result oriented and effective for development of the country, it is important to train teachers with ICT and provide enough resources for training.

\subsection{Strengthened Academic Research and Develop Interactive Contents}

Research is one of the primary task in university level and essential for the real development of education. Research maximizes education opportunities and paves the way for sustainable development. MoHE must provide opportunities for lecturers and professors to ensure, improve and survive learning 
and teaching through variety of research. Learning Analytics is the latest topic in teaching and learning today; that value to the quality of teaching. Research in such area may guaranty learner's performance in real-time and help them to understand the effectiveness of learning [10]. Moreover, collection of data from Learning Analytics depend on specific goal and much of the data comes from online education systems. Therefore there is a dire need to develop interactive data and consider the most appropriate data sources like quizzes, grade-book scores, enrollments, and online student's feedback and so on, in analytics.

\subsection{Improved Quality Control and Accreditation}

Accreditation refers to an external review process of higher education institutions and programs to ensure quality improvement and matched by qualitative standards from the viewpoint of professors, teaching, research, service delivery as well as infrastructure, accountability, Sustainability, achievements and compliance with applicable laws. MoHE must focus for accreditation of institution in Afghanistan in order to make them compete with each other and ensure the quality of education.

\section{CONCLUSION}

In this decade, the price for the ICT devices and Internet connection decreased even in developing countries and the needs for ICT literacy increased dramatically. Integration and use of ICT in education will foster efficiently the human resource of future, and contribute effectively to the economic and social development Clear policy, structured plan and devotion are necessary to achieve this innovation of education.

Implementation of e-learning systems in in Afghanistan is strongly recommended. Furthermore, for effectiveness of elearning systems and to ensure the efficiency of LMS to learner's behaviors it is recommended to consider the concept of Learning Analytics in teaching and learning environment.

Finally, to implement effective ICT solutions, the problems pointed out in this study should be considered and the possible solutions suggested can be applied to overcome some of the challenges.
In compliance of the current requirements and needs of Afghanistan higher education, analyzing and evaluating the effectiveness of e-learning systems particularly, LMS builds an image to achieve learning goals and improve learning and teaching. For future work, my next objective is to focus to the analytical strategy, particularly Learning Analytics. Since Learning Analytics enable the academies to realize the learning environments through measurement, collection, analysis and reporting of data about learners and their contexts.

\section{REFERENCES}

[1] Peroz, N. 2015. Strategic Framework for the Employment of E-learning Projects in Afghanistan Challenges and Requirements. TU Berlin, Berlin.

[2] Corbett, C. 2014. USAID Afghanistan. Washington, DC.

[3] Human Development Report. 2014. International Human Development Indicators. [Online] Available at: http://hdr.undp.org/en/countries].

[4] The United Nation International Children's Emergency Fund (Unicef). 2011. Education in Afghanistan.

[5] Beebe, M. 2009. E-learning in Afghanistan.

[6] Mikawa, S. 2006. Cisco-USAID-UNDP Networking Academy Alliance, Developing a sustainable Cisco Networking Academy Program in Afghanistan. Kabul.

[7] Muga, T. O. 2009. E-learning Readiness Assessment: A Case of Higher Education Institutions in Kabul, Afghanistan. University of Nairobi, School of Computing and Informatics.

[8] Kankor. (2012). Kankor Afghanistan. [Online] Available at: http://www.mohe.gove.af.

[9] Ministry of Higher Education (MoHE). 2015. E-Learning strategy plan for higher education of Afghanistan.

[10] Mwalumbwe, I., \& Mtebe, J. 2017, March. Using Learning Analytics to Predict Students' Performance in Moodle Learning Management System: A Case of Mbeya University of Science and Technology. Electronic Journal of Information Systems in Developing Countries. 